\title{
Directed Energy Systems
}

\author{
Matthew N. O. Sadiku ${ }^{1}$, Kazeem B. Olanrewaju ${ }^{2}$ and Sarhan M. Musa ${ }^{3}$ \\ ${ }^{1,3}$ Department of Electrical and Computer Engineering, Prairie View A\& M University \\ ${ }^{2}$ Department of Chemical Engineering, Prairie View A \& M University, \\ College of Engineering \\ Prairie View, Texas
}

USA

\begin{abstract}
Directed energy $(D E)$ is an umbrella term covering technologies that produce concentrated electromagnetic energy. A DE system uses DE primarily as a means to disable, damage, or destroy enemy equipment, facilities and personnel. The US, as well as other nations, including the UK, Germany, France, Russia, and China, have all been engaged in long-standing research and development into direct energy systems. This paper provides an introduction on directedenergy systems, their applications, and challenges.
\end{abstract}

Key Words: Directed Energy, Directed-Energy Systems, Directed-Energy Weapons, Directed Energy Deposition.

\section{INTRODUCTION}

Profound advancements are occurring in science and technology at an extremely rapid pace. Some perceive technological threats of biotechnology, nanotechnology, and directed energy. Direct energy (DE) promises to be a transformational "game changer," while facing some traditional challenges. Two different forms of directed energy represent threats to military and civilian personnel: the pulsed type and continuous, the most common being lasers [1]. The lasers are mostly range finding systems designed to improve the capability and effectiveness of kinetic weapons or dazzlers designed to incapacitate enemy optics. They emit narrow beams of monochromatic (single-wavelength) light, which can focus energy precisely on a designated point. Recent advances have made lasers a leading candidate for directed-energy applications.

Directed energy technologies are advancing rapidly and are now beginning to be applied for military purposes. Directed-energy systems support US national security priorities. The Pentagon is seeking to boost its directed-energy capabilities and exploring ways to give our warfighters an advantage.

Directed-energy is used in many applications such ballistic missile in space, electric propulsion, directed energy weapons, space-based weapons, tactical defense, power beaming, additive manufacturing, directed energy deposition, directed energy transfer, global information grid, and planetary defense. Some of these will be considered in this paper.

\section{DIRECTED ENERGY WEAPONS}

Warfighters have often leveraged technology to increase their advantage on the battlefield. Some key technologies have underwritten US supremacy - precision strike, satellites, GPS, and advanced communications. As conventional weapons are nearing their peak technical capability, the US military must make smart investment in research and development in the years ahead. Directed-energy weapons are one of a broader set of tools in the warfighter's toolbox [2]. Examples of directed-energy weapons are shown in Figure 1 [3]

A directed-energy weapon (DEW) is a system using DE primarily as a means to disable, damage, or destroy enemy equipment, facilities, and personnel. DEWs are electromagnetic systems capable of converting chemical or electrical energy to radiated energy and focusing it on a target. It transfers energy to a target for a desired effect on humans, which may be lethal or non-lethal. The energy can come in various forms such electromagnetic radiation, microwave, lasers, and maser. Because DEWs are based on radiated energy, the operator can vary the beam to achieve specific result. The effectiveness of an airborne DEW is determined by 
its ability to deliver electromagnetic radiation of sufficient power density to a target. DEW would replace the nuclear monsters soon

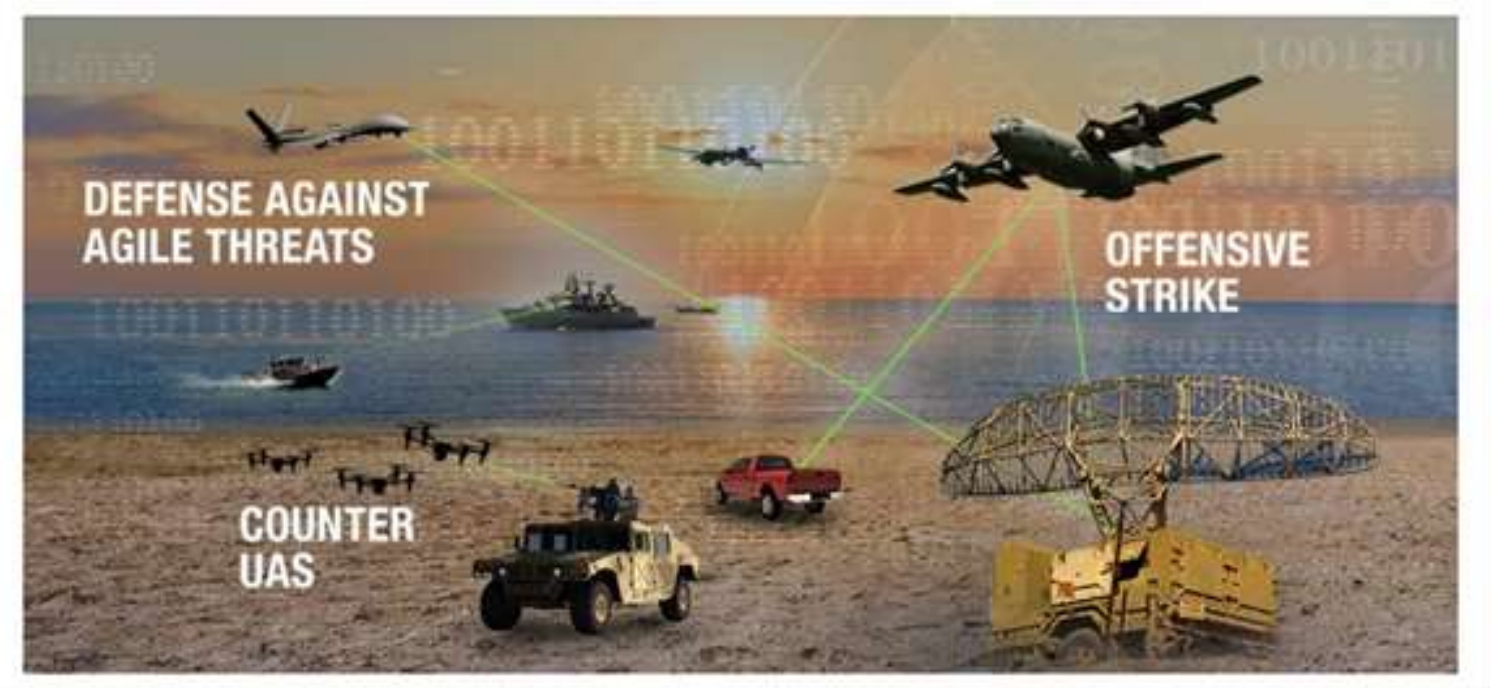

Figure 1: Examples of directed-energy weapons [3]

enough [4]. Directed-energy weapons have some advantages over conventional weapons including precision, non-lethal, low cost per shot, and scalable effects. They can serve as a cost-effective counter to enemy ballistic missiles and preempt enemy use of weapons of mass destruction.

Common DEWs include electromagnetic railgun (EMRG), high-energy lasers (HEL), low-energy laser (LEL), high-power microwave devices (HPM), active denial system (ADS), and radio frequency munitions (RFM).

- Electromagnetic Railguns (EMRG): This is a weapon that damages its target with highly focused energy. It is a technology that fires projectiles using electricity instead of chemical propellants. EMRG have primarily focused on three main wavelength bands: infrared lasers, microwaves, and millimeter waves. The railgun can hit ranges of 100 nautical miles or more. Radio-frequency weapons propagate intense bursts of energy that disable or destroy electronics. Potential applications of this technology include weapons that target vehicles and missiles. Future railgun will fire 10-shots-perminute and automatically reloads.

- Hight-Energy Laser (HEL): This technology is used in scientific research and defense. It is achieved by various means like chemical reaction, electrical currents or intense light. Airborne HELs could change the very nature of air combat. It was created by Boeing for the US Army. Lockheed Martin is also involved in the development of HEL. The HEL has the potential to effectively counter rocket, artillery, and mortar projectiles. Chemical HEL systems have been demonstrated [5].

- High-Power Microwaves (HPM): This is another DEW technology. It releases radio frequency waves or microwaves to targets which may be military or civilians and disable them. HPM sources are often energized by pulsed power systems with applied voltages in the $100 \mathrm{kV}$ to $1 \mathrm{MV}$ range. HPMs could be used to defend US aircraft against surface-to-air missiles. They could attack virtually any electronic system without doing direct harm to nearby civilians [5].

- Active Denial System (ADS): This is a DEW system that is available, fielded and ready for combat. The ADS was designed and tested by Raytheon. ADS sends an extremely high frequency and focused beam of $95 \mathrm{GHz}$ waves at a person, or group of people, causing intense pain. The targeted energy causes skin surface temperature to rise and become so uncomfortable in a few seconds that people are forced to leave the target area [6].

The United States, the United Kingdom, Russia, China, India, Israel, France, and South Korea are developing directed-energy weapons. Directed-energy research is going on in many countries. However, the expectations made on such weapons could not be matched by their performance. Basic constraints include beam attenuation, limited range, and an inability to be employed against non-line-of-sight targets.

\section{SPACE-BASED WEAPONS}

The main idea behind militarizing outer space is that it offers some unique advantages.

Military targets must be protected from high-energy light pulses that propagate efficiently across space at high speed. Targets may include personnel, vehicles, missiles, aircraft, and satellites. Examples of directed-energy space weapons are shown in Figure 2 [7]. 
The enthusiasm for lasers in space was incited by US President Ronald Reagan when he gave a famous "Star Wars" advocating a strategic defense initiative that included lasers in space to shoot down incoming Soviet nuclear missiles. The dream of spacebased lasers continued in both military and non-military minds. After the Soviet Union faded away, the Pentagon came up with new enemies (such as rogue states and insurgents) and started to develop laser weapons to defend against them. The perceived vulnerability of space-based systems is of increasing concern. Most lasers run on electricity, and the needed power is not easy to come by in space [8].

Some critics have seen spaced-based weapons as a means of engaging military, in the case of lasers. The space race is not limited to US. In addition to the established space-operating nations of the US, UK, Russia, France, Germany, and Israel, other nations such as China and India now possess space capabilities [9].

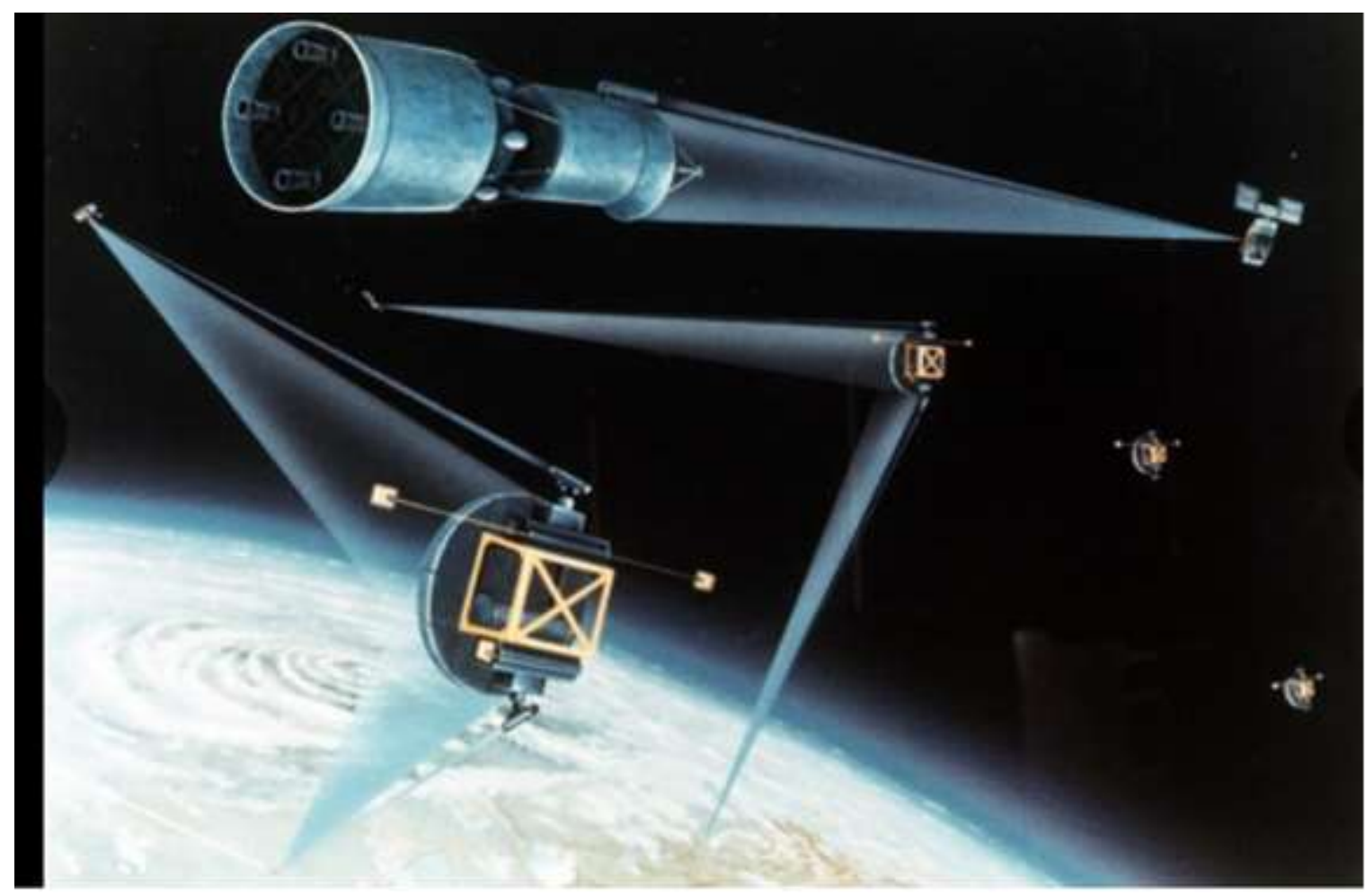

Figure 2: Directed-energy space weapons [7].

\section{DIRECTED ENERGY DEPOSITION}

Additive manufacturing (AM) is an advanced technique used in the automotive industry due to the opportunities it offers. Laser additive manufacturing (LAM) is a processes where three-dimensional (3D) metallic components can be produced through layer by layer deposition of material using heat from a laser source. Directed energy deposition (DED) is a primary LAM technology [10]. Among AM technologies, DED has gained at lot attention in recent years as a novel and promising technique to produce or repair the complex metallic parts. Figure 3 shows the directed energy deposition process [11].

Directed energy deposition (DED) is also a form of direct manufacturing technique. It is a process in which the material is delivered directly into the melt pool. It is capable of producing complex components efficiently. DED processes are evaluated for additive manufacturing and are able to produce complex components. DED technology is often utilized to coat metallic part with complex geometries in a variety of anti-corrosion materials or high-temperature materials. It is also utilized for 3D printing/fabrication of dissimilar alloy walls. DED is setting a trend for the repair and restoration of high value components [12].

Laser additive manufacturing using DED process uses laser beam to melt powder. The laser-based DED process has the advantages of geometric flexibility and low lead time over conventional manufacturing practices. Laser systems are viewed as a complement to existing weapons, rather than as direct replacements. Laser directed energy deposition technology overcomes the size and geometry limitations of bulk metallic glasses. DED is often used to coat metallic part with complex geometries in a variety of anti-corrosion materials or high-temperature materials [13].

Metallic AM parts are now used within many industrial sectors such as automotive, dental, medical, and aerospace. AM parts manufactured using the DED technologies may be unsuitable and unreliable to meet the stringent requirements for many industrial or mission-critical applications [14] 
International Journal of Advances in Scientific Research and Engineering (ijasre), Vol 5 (10), October-2019

\section{BENEFITS AND CHALLENGES}

Directed-energy systems and weapons offer a unique response to rapidly emerging global threats. Using directed-energy weapons will provide US military forces with the ability to effectively fight in an urban environment while minimizing non-combatant casualties and reducing local infrastructure damage. High power, large aperture DE systems are being used to propel spacecraft.

Directed energy weapons are now becoming more mature and better understood, yet misconceptions about them remain. Some skeptics perceive that directed energy weapons may surpass nuclear weapons in the risk they pose to the United States and humankind. They may pose a risk to satellite operations. After several years of research, directed-energy weapons are still at the experimental stage and have not yet been deployed as practical, military weapons. Most directed-energy projects have been canceled and never went beyond the experimental stage or are only used in niche applications [15]. In addition, current budgetary constraints,

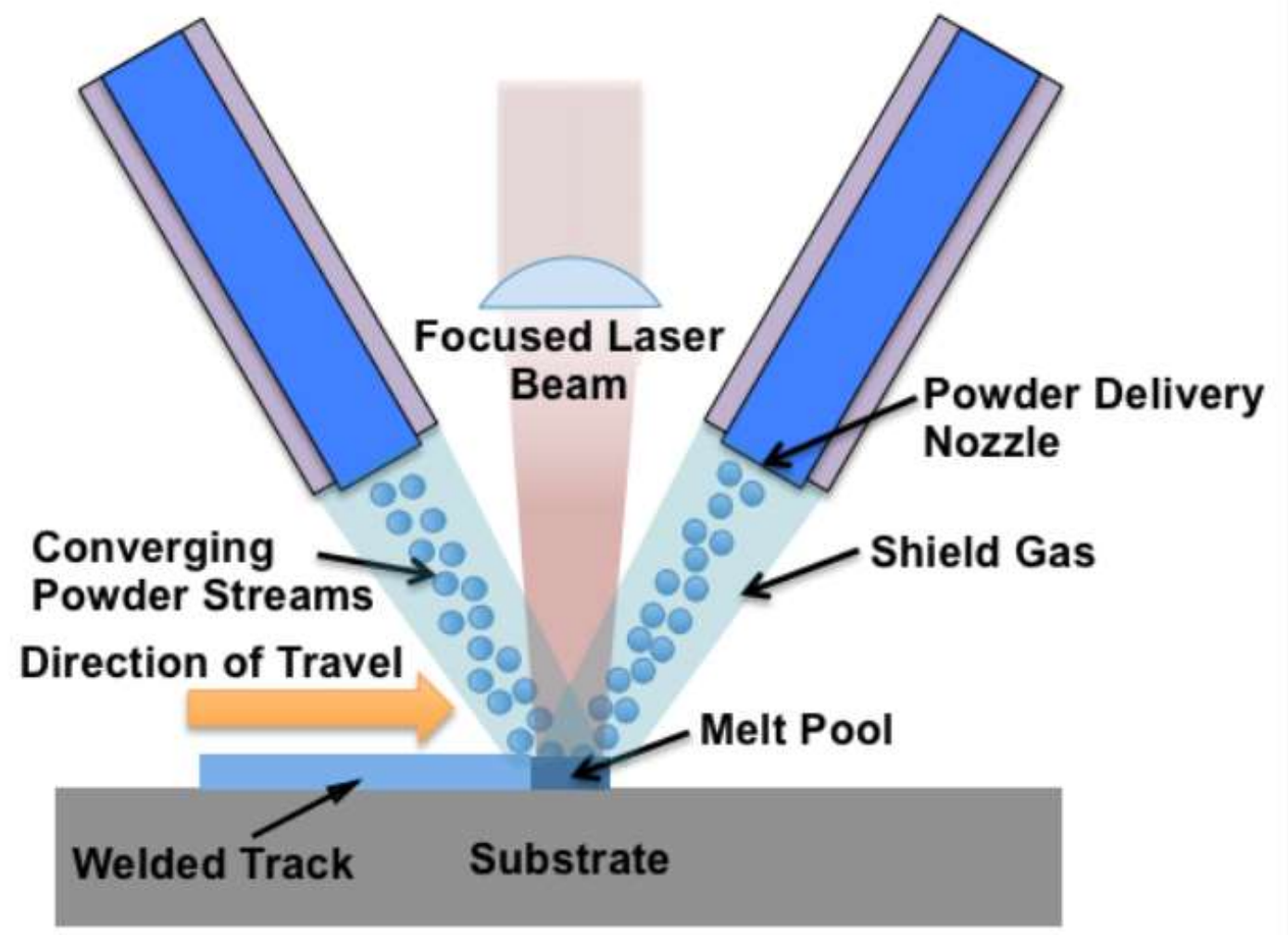

Figure 3: Directed energy deposition process [11]

fear, due to a lack of understanding of DEW technology are leading to a decrease in DEW research and development. Due to these challenges, it is difficult to forecast the future of directed energy with certainty. Before DEW can replace gunpowder as war technology, the issues of power, heat, size, and inclination must be addressed and overcome. This will make these weapons effective across the entire spectrum of combat operations. The US military should increase DEW funding as well as continue to research and integrate directed-energy weapons in their training and operations [16].

\section{CONCLUSION}

The time has arrived for directed energy to make the leap from successful demonstrations to equipping the soldiers who are defending our nation. It will play a unique role for national security. In the long run, we will benefit greatly from it. It is well known that a technological innovation will either prove itself viable within the framework of military policy or become extinct. DE systems are a fast-approaching reality and they will likely attract increased attention from militaries and governments seeking to establish technical superiority over adversaries. More information about direct-energy technologies can be found in the books in [17-21].

\section{REFERENCES}

[1] J. P. Geis and T. C. Hailes, "Deterring emergent technologies,"

https://www.airuniversity.af.edu/Portals/10/SSQ/documents/Volume-10_Issue-3/Geis.pdf

[2] J. D. Ellis, Directed-energy weapons: promise and prospects,” April 2015,

https://www.files.ethz.ch/isn/190363/CNAS_Directed_Energy_Weapons_April-2015.pdf

[3] "Directed energy weapons (DEW)," 
International Journal of Advances in Scientific Research and Engineering (ijasre), Vol 5 (10), October-2019

https://www.ara.com/projects/directed-energy-weapons-dew

[4] C.N. Ghosh, "Directed energy weapons," Strategic Analysis, vol. 24, no. 11, 2001, pp. 2055-2072.

[5] A. Feickert, "U.S. Army weapons-related directed energy (DE) programs: Background and potential issues for Congress," February 2018,

https://fas.org/sgp/crs/weapons/R45098.pdf

[6] J. Antal, "Today's directed energy weapons meeting the realities of power, heat, size and inclination," Military Technology, October 2013, pp. 26-27.

[7] B. Sweetman, "Directed-energy weapons: No longer science fiction,” August 2015, https://aviationweek.com/AdvancedWeapons\#slide-0-field_images-1341101

[8] J. Hecht, "A 'Star Wars' sequel? The allure of directed energy for space weapons," Bulletin of the Atomic Scientists, vol. 75, no. 4, 2019, pp. 162-170.

[9] Anoumous, "Chapter one: Directed energy weapons: Finally coming of age?” The Military Balance, vol. 115, no. 1, 2015, pp. 9-20.

[10] A. Saboori et al., "An investigation on the effect of powder recycling on the microstructure and mechanical properties of AISI 316L produced by directed energy deposition," Materials Science and Engineering: A, vol 766, October 2019.

[11] "High level processes: Directed energy deposition," April 2017, https://www.bintoa.com/directed-energy-deposition/

[12] S. Alya et al., "Characterization and modeling of deposition geometry in directed energy deposition over inclined surfaces," Procedia Manufacturing, vol. 34, 2019, pp. 695-703.

[13] W. Li and M. Soshi, "Modeling analysis of grain morphologies in directed energy deposition (DED) coating with different laser scanning patterns," Materials Letters, vol. 251, September 2019, pp. 8-12.

[14] M. Khanzadeh et al., "In-situ monitoring of melt pool images for porosity prediction in directed energy deposition processes," IISE Transactions, vol. 51, no. 5, 2019, pp. 437-455.

[15] "Directed-energy weapon," Wikipedia, the free encyclopedia https://en.wikipedia.org/wiki/Directed-energy_weapon

[16] S. D. Davis, "Controlled warfare: How directed-energy weapons will enable the US Military to fight effectively in an urban environment while minimizing collateral damage," Small Wars \& Insurgencies, vol. 26, no. 1, 2015, pp. 49-71.

[17] Y. Pauleau, Materials Surface Processing by Directed Energy Techniques. London, UK: Elsevier, 2006.

[18] B. Zohuri, Directed Energy Weapon Technologies. Boca Raton, FL: CRC Press, 2012.

[19] B. Zohuri, Directed Energy Weapons. Springer, 2019.

[20] B. Zohuri,, High Energy Laser (HEL): Tomorrow's Weapon in Directed Energy Weapons. Trafford, volume I, 2014.

[21] D. Beason, The E-Bomb: How America's New Directed Energy Weapons Will Change the Way Future Wars Will Be Fought. Cambridge, MA: Da Capo Press, 2005. 